\title{
Compensating functional iron deficiency in patients with allergies with targeted micronutrition
}

\author{
Franziska Roth-Walter
}

Received: 3 February 2021 / Accepted: 1 March 2021 / Published online: 20 April 2021

(C) The Author(s) 2021

\begin{abstract}
Summary Iron deficiency is associated with atopy. Iron deficiency during pregnancy increases the risk of atopic diseases in children, while both allergic children and adults are more likely to have iron deficiency anemia. Immunologically, iron deficiency leads to activation of antigen-presenting cells, promotion of Th2 cells and enables antibody class switch in B cells. In addition, iron deficiency primes mast cells for degranulation, while an increase in their iron content inhibits their degranulation. Many allergens, especially those with lipocalin and lipocalin-like protein structures, are able to bind iron and either deprive or supply this trace element to immune cells. Thus, a local induced iron deficiency will result in immune activation and allergic sensitization. However, lipocalin proteins such as the whey protein $\beta$-lactoglobulin (BLG) can also transport micronutrients into the defense cells (holo-BLG: BLG with micronutrients) and hinder their activation, thereby promoting tolerance and protecting against allergy. Since 2019, several clinical trials have also been conducted in allergic subjects using holo-BLG as a supplementary balanced diet, leading to a reduction in symptom burden. Supplementation with holo-BLG specifically supplied defense cells with micronutrients such as iron and therefore represents a new dietary approach to compensate for functional iron deficiency in allergy sufferers.
\end{abstract}

\footnotetext{
F. Roth-Walter, $\mathrm{PD} \mathrm{PhD}(\bowtie)$

Comparative Medicine, The Interuniversity Messerli Research Institute, University of Veterinary Medicine Vienna, Medical University Vienna and University of Vienna, Vienna, Austria

Institute of Pathophysiology and Allergy Research, Medical University Vienna, Vienna, Austria

franziska.roth-walter@meduniwien.ac.at
}

Keywords Atopy $\cdot \beta$-Lactoglobulin $\cdot$ Holo-BLG $\cdot$ Mast cells $\cdot$ Micronutrients $\cdot \mathrm{T}$ helper type 2 cells

$\begin{array}{ll}\text { Abbreviations } \\ \text { AID } & \text { Activation-induced cytidine deaminase } \\ \text { BLG } & \beta \text {-Lactoglobulin } \\ \text { FSMP } & \begin{array}{l}\text { Food for special medical purpose (bal- } \\ \text { anced diets) }\end{array} \\ \text { holo-BLG } & \begin{array}{l}\text { Loaded } \beta \text {-lactoglobulin } \\ \text { IgE }\end{array} \\ \text { Immunoglobulin E } \\ \text { MC } & \text { Lipocalin-2 } \\ \text { Th1 } & \text { Mast cells } \\ \text { Th2 } & \text { T helper type 1 cells } \\ & \text { T helper type } 2 \text { cells }\end{array}$

\section{Introduction}

It is still unclear why the defense system of atopic subjects reacts so excessively to environmental triggers that their risk of developing allergies is increased. Female gender, low microbial exposure and the molecular properties of allergens themselves are well-established risk factors for patients with allergies [1].

In contrast, growing up on a farm [2] with many siblings [3], and pets [4] protects against atopic diseases. Also drinking of raw milk, particularly with high whey content, is a known independent factor that protects against allergy development [5].

Also nutritional deficiencies, particularly of micronutrients such as vitamin D [6], $\beta$-carotenoidswhich are precursors of vitamin A-[7] as well as a deficiencies of iron and folate are associated with atopy [1, 8-11].

There exist two entities of iron deficiency: (a) absolute iron deficiency and (b) functional iron deficiency, whereby different degrees and mixed forms occur between these two forms. In the case of absolute iron deficiency, also known as anemia, the iron stores are 
empty, whereas functional iron deficiency means that the iron reserves are not exhausted, but these iron reserves cannot be mobilized and are not accessible for cellular functions [1].

This situation is often encountered in cancer patients and in people with chronic inflammation.

\section{Iron deficiency and allergy-clinical evidence}

In recent years, large epidemiological studies with children have demonstrated that children with allergies have an up to 8-fold higher risk of being affected by iron deficiency anemia than children without allergies [10, 12]. Already the iron status of pregnant women has an impact on the later risk to develop allergies in children. Several studies demonstrated that that the improved iron status of the expectant mother [8, 13-16] went along with a reduced risk of developing atopic dermatitis or asthma in the children. An inverse association also existed between the level of iron in the umbilical cord blood at delivery and the development of atopic urticaria, infantile eosinophilia and asthma at age $6[9,16]$. Even in adults, the risk of suffering from iron deficiency anemia persist with allergic males having a 3.5-fold higher risk, whereas in allergic females the risk of anemia is "only" increased by about $66 \%$ [17].

In summary, in all the epidemiological and clinical studies, iron deficiency is a constant companion of atopic individuals and contributes to their increased risk to develop allergy.

\section{Iron deprivation in immune cells favors development of allergies}

To understand the fine-tuning role of iron-or better the lack of iron-with the increased risk to develop atopic diseases, one must examine more closely the influence of iron deficiency on our immune cells.

\section{Iron deficiency favors sensitization}

Allergy can only develop when concurrent to allergen exposure (1) a Th2 dominance prevails, which is characterized by the release of Th2-associated mediators such as interleukin-4 and (2) the antibody-producing B cells perform a class switch towards immunglobulin E (IgE)-antibody production.

From cell culture studies it is known that under iron-deficient conditions, especially Th2 cells rather than other T-cells survive under these harsh conditions and thus their survival is favored [18-23]. Importantly, the preclinical studies have been replicated in a clinical study that examined blood cells from healthy children with or without iron deficiency. In that study, interleukin-4 was significantly elevated in healthy, iron-deficient compared to iron-repleted children [24]. Consequently, iron deficiency per se favors
Th2 dominance and thus the first prerequisite for allergic sensitization (Fig. 1).

The antibody-producing B cells are relatively unaffected by iron deficiency. However, they do possess an enzyme which is responsible for class switching as well as affinity maturation of antibodies, the activation-induced cytidine deaminase, AID. Iron specifically suppresses the activation of this enzyme; in the absence of iron, the deaminase is activated [25] and class switching to immunoglobulin class E (IgE) occurs (Fig. 1).

Finally, when a protein gets to the immune cells under iron-deprived conditions, this antigen becomes an allergen and the person becomes sensitized to it.

\section{Iron-deficiency primes mast cells}

Iron deficiency also affects the cells which are mainly responsible for allergic reactions, the mast cells. Intradermal application of the iron binder, desferrioxamine, induces local iron deficiency and results in histamine release and wheal formation [26]. In fact, this iron binder, now used to treat chronic iron overload, is so effective in activating mast cells that there have been efforts at times to use it as a positive control instead of histamine for skin testing. In turn, the activation of mast cells can be hampered by the addition of iron-containing proteins such as transferrin, lactoferrin, as well as by the iron-loaded whey protein $\beta$-lactoglobulin (holo-BLG) [27-32].

Thus, the extent of iron repletion in mast cells determines their priming state to release mediators such as histamine that are responsible for allergy symptoms (Fig. 1).

\section{Lipocalins transport micronutrients to immune cells}

Only very few protein families are prone to become allergens. Consequently, almost all major allergens of animal origin belong to the lipocalin family.

Lipocalin- and lipocalin-like proteins possess a calyx, which enables them to bind to micronutrient such as iron [33, 34] and retinoic acid [35, 36] and to deliver, but also sequester these micronutrients specific to, but also from immune cells [32, 36, 37].

A human analogue of BLG is lipocalin-2 (LCN2) [38], which is an acute phase protein, that is abundantly secreted during infections. As an innate defense protein, it withholds nutrients from pathogens and thereby acts bacericidic. However, in allergic people too little LCN2 is present in their blood [39]. The whey protein BLG seems to have a similar function as LCN2 which is to protect the calf against infections. Upon dietary ingestion, BLG, due to its similarity to human lipocalin proteins, is primarily transported via the lymphatic vessels directly to the human immune cells. There, like LCN2, it can provide its micronutrients in a receptor-mediated manner to immune cells 


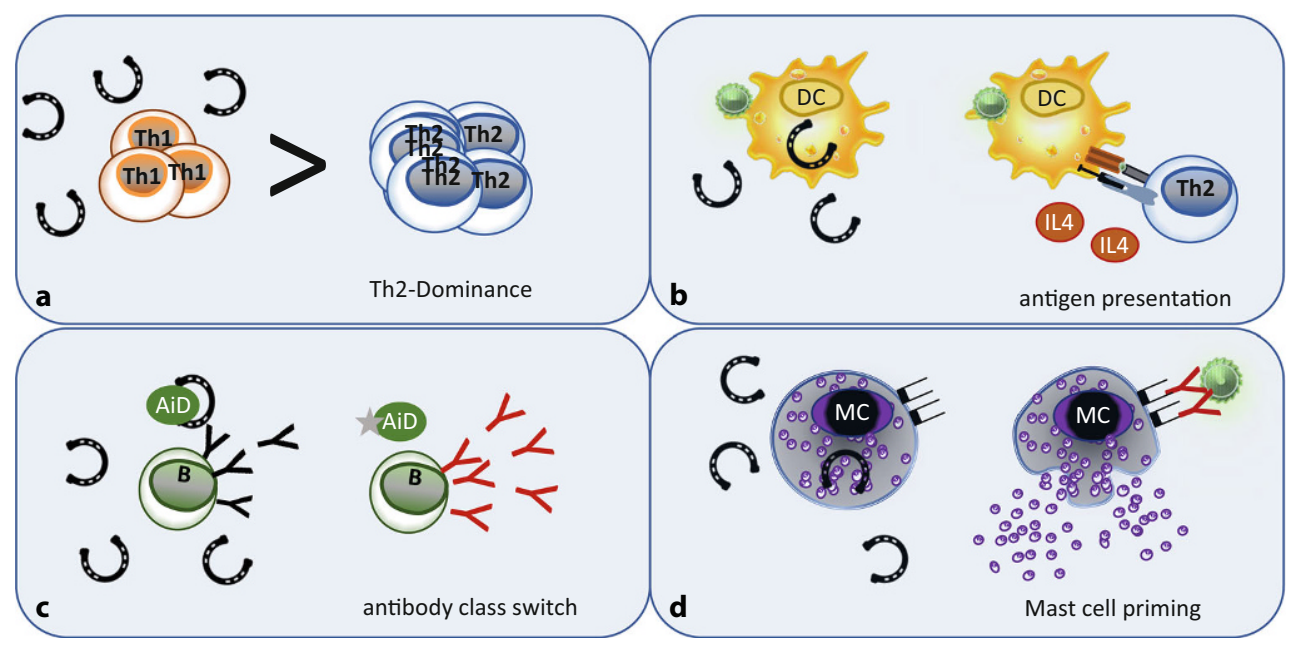

Fig. 1 Impact on iron on immune cells. a Th2 cells, which are crucial for allergy development, have a survival advantage over Th1 cells under iron-deficient conditions. b Antigen presentation and thus immune activation is hampered by increasing intracellular iron levels in antigen-presenting cells (DC). c In $B$ cells, iron suppresses the activation of the activation-in-

such as macrophages or mast cells that have this nutrient requirement. Thus, holo-lipocalins contribute with their transport function to the proper equilibrium of our immune system via targeted micronutrition.

\section{Targeted provision of micronutrients via holo- BLG prevents allergies-preclinical studies}

In our recent murine studies, BLG only became an allergen when it was not loaded with micronutrients such as iron or vitamin A [36]. However, once the BLG pocket was loaded with iron complexes (holo-BLG), it prevented allergy development by directly transporting its micronutrition cargo to the immune cells, where it initiated anti-inflammatory, tolerogenic signaling pathways [32].

Interestingly, carrying these micronutrients in holoBLG also covered parts of the BLG surface and thus IgE epitopes. As a result, IgE antibodies from sera of milk-allergic children with a positive reaction to milk recognized the holo-BLG more poorly than antibodies from children who were milk-sensitized but who tolerated milk. This suggests that exposure to BLG without ligands was the primary cause for sensitization as IgE was generated to the empty form in milkallergic children.

In addition, we showed that loading BLG with iron complexes also increased the iron content of immune cells, while simultaneously immune activation was inhibited (Fig. 1) [32].

In another mouse study, prophylactic treatment with holo-BLG also protected against any subsequent allergic sensitization. Micronutrient supplementation inhibited the activation of antigen-presenting cells in an antigen-independent manner, so that specific duced cytidine deaminase (AiD), an enzyme which is responsible for the class switch to lgE as well as for affinity maturation. d A local induced iron depletion activates mast cells (MC) to degranulate. Conversely, iron supplementation decreases mast cell degranulation. (Note: The small horseshoes stand for iron)

antibody development against different allergens was also significantly suppressed [40].

Thus, these preclinical cellular and murine studies all showed that by targeting iron to immune cells, allergies were prevented and alleviated from allergic symptoms in an antigen-unspecific manner [32, 35, $40,41]$.

\section{Directing micronutrient with BLG to immune cells as therapeutic approach-clinical studies}

Based on the preclinical data, several clinical studies have been conducted since 2019 demonstrating the efficacy of holo-BLG in lozenge form (ImmunoBON ${ }^{\circledR}$ ). In a double-blind, placebo-controlled study with pollen allergic women taking holo-BLG lozenges for 6 months, micronutrient supplementation with holoBLG not only reduced the daily symptom burden during the birch pollen season, but also led to an increase in iron levels in the antibody-producing B cells [32, 35, 41]. Likewise, in house dust mite allergic patients, whose symptoms were studied before and after 3 months of holo-BLG in an allergen exposure chamber, a significant reduction in symptom burden were noted [42]. Due to the scientifically and clinically proven benefit, the holo-BLG lozenge is now available as food for special medical purpose (FSMP) (balanced diets) for patients with seasonal and perennial allergy.

\section{Conclusion}

Functional iron deficiency not only facilitates allergy development, but also heightens the clinical symptom burden in allergy sufferers. Our preclinical as well as clinical studies document that iron can be selectively delivered to the immune cells by holo-BLG. 
This results in immune resilience in an antigen-independent manner that allows the immune system to return to a normal and healthy status (= homeostasis). Indeed, this mode of action completely redefines our understanding of allergies. The allergen-independent mechanism of targeted micronutrition, can be used alongside specific allergen immunotherapy to combat allergies.

Funding Open access funding provided by University of Veterinary Medicine Vienna.

Conflict of interest F. Roth-Walter is the main inventor of EP2894478 (applicant Biomedical International R+D $\mathrm{GmbH}$, Vienna, Austria), the basis for the FSMP lozenge ImmunoBON ${ }^{\circledR}$. F. Roth-Walter has been conducting clinical studies on this topic since 2017 and has received research funding from Biomedical International R+D GmbH, Vienna, Austria, Bencard Allergie GmbH, Munich, Germany and Vienna, Austria, and Allergy Therapeutics, Worthing, UK.

Open Access This article is licensed under a Creative Commons Attribution 4.0 International License, which permits use, sharing, adaptation, distribution and reproduction in any medium or format, as long as you give appropriate credit to the original author(s) and the source, provide a link to the Creative Commons licence, and indicate if changes were made. The images or other third party material in this article are included in the article's Creative Commons licence, unless indicated otherwise in a credit line to the material. If material is not included in the article's Creative Commons licence and your intended use is not permitted by statutory regulation or exceeds the permitted use, you will need to obtain permission directly from the copyright holder. To view a copy of this licence, visit http://creativecommons.org/licenses/by/4.0/.

\section{References}

1. Roth-Walter F, Pacios LF, Bianchini R, Jensen-Jarolim E. Linkingiron-deficiency with allergy: role of molecular allergens and the microbiome. Metallomics. 2017;9:1676-92.

2. Strachan DP. Hay fever, hygiene, and household size. BMJ. 1989;299:1259-60.

3. Ownby DR, Johnson CC, Peterson EL. Exposure to dogs and cats in the first year of life and risk of allergic sensitization at 6 to 7 years of age. JAMA. 2002;288:963-72.

4. LossG,ApprichS, WaserM, KneifelW, GenuneitJ,BucheleG, et al. The protective effect of farm milk consumption on childhood asthma and atopy: the GABRIELA study. JAllergy Clin Immunol. 2011;128:766-73.e4.

5. RiedlerJ,Braun-FahrlanderC,EderW, SchreuerM, WaserM, Maisch S, et al. Exposure to farming in early life and development of asthma and allergy: a cross-sectional survey. Lancet. 2001;358:1129-33.

6. Smith M, O'Brien EC, Alberdi G, Geraghty AA, Kilbane M, McKenna MJ, et al. Association between vitamin D status in early pregnancy and atopy in offspring in a vitamin D deplete cohort. Ir J Med Sci. 2020;189:563-70.

7. Nurmatov U, Devereux G, Sheikh A. Nutrients and foods for the primary prevention of asthma and allergy: systematic review and meta-analysis. J Allergy Clin Immunol. 2011;127:724-33.e1-30.

8. Shaheen SO, Newson RB, Henderson AJ, Emmett PM, Sherriff $\mathrm{A}$, Cooke $\mathrm{M}$, et al. Umbilical cord trace elements and minerals and risk of early childhood wheezing and eczema. Eur Respir J.2004;24:292-7.
9. Weigert R, Dosch NC, Bacsik-Campbell ME, Guilbert TW, Coe CL, Kling PJ. Maternal pregnancy weight gain and cord blood iron status are associated with eosinophilia in infancy. J Perinatol. 2015;35:621-6.

10. Drury KE, Schaeffer M, Silverberg JI. Association between atopic disease and anemia in US children. JAMA Pediatr. 2016;170:29-34.

11. Oh SY, Chung J, Kim MK, Kwon SO, Cho BH. Antioxidant nutrient intakes and corresponding biomarkers associated with the risk of atopic dermatitis in young children. Eur J Clin Nutr. 2010;64:245-52.

12. Rhew K, Oh JM. Association between atopic disease and anemia in pediatrics: a cross-sectional study. BMC Pediatr. 2019;19:455.

13. Fortes C, Mastroeni S, Mannooranparampil TJ, Di Lallo D. Pre-natal folic acid and iron supplementation and atopic dermatitis in the first 6 years of life. Arch Dermatol Res. 2019;311:361-7.

14. Bedard A, Lewis SJ, Burgess S, Henderson AJ, Shaheen SO. Maternal iron status during pregnancy and respiratory and atopic outcomes in the offspring: a Mendelian randomisation study. BMJ Open Respir Res. 2018;5:e275.

15. Shaheen SO, Macdonald-Wallis C, Lawlor DA, Henderson AJ. Haemoglobin concentrations in pregnancy and respiratory and allergic outcomes in childhood: birth cohort study. Clin Exp Allergy. 2017;47:1615-24.

16. Nwaru BI, Hayes H, Gambling L, Craig LC, Allan K, Prabhu N, et al. An exploratory study of the associations between maternal iron status in pregnancy and childhood wheeze and atopy. Br J Nutr. 2014;112:2018-27.

17. Rhew K, Brown JD, Oh JM. Atopic disease and anemia in Korean patients: cross-sectional study with propensity score analysis. Int J Environ Res Public Health. 2020;17:1978.

18. Thorson JA, Smith KM, Gomez F, Naumann PW, Kemp JD. Role of iron in $\mathrm{T}$ cell activation: TH1 clones differ from TH2 clones in their sensitivity to inhibition of DNA synthesis caused by IgG Mabs against the transferrin receptor and the iron chelator deferoxamine. Cell Immunol. 1991;134:126-37.

19. Weiss G, Bogdan C, Hentze MW. Pathways for the regulation of macrophage iron metabolism by the anti-inflammatory cytokines IL-4 and IL-13. J Immunol. 1997;158:420-5.

20. Jason J, Archibald LK, Nwanyanwu OC, Bell M, Jensen RJ, Gunter E, et al. The effects of iron deficiency on lymphocyte cytokineproduction andactivation: preservation ofhepatic iron but not at all cost. Clin Exp Immunol. 2001;126:466-73.

21. Leung S, Holbrook A, King B, Lu HT, Evans V, Miyamoto N, et al. Differential inhibition of inducible T cell cytokine secretion by potent iron chelators. J Biomol Screen. 2005;10:157-67.

22. Piantadosi CA, Withers CM, Bartz RR, MacGarvey NC, Fu P, Sweeney TE, et al. Heme oxygenase-1 couples activation of mitochondrial biogenesis to anti-inflammatory cytokine expression. J Biol Chem. 2011;286:16374-85.

23. Elmadfa I, Meyer AL. The role of the status of selected micronutrients in shaping the immune function. Endocr Metab Immune Disord Drug Targets. 2019;19:1100-15.

24. Nyakeriga AM, Williams TN, Marsh K, Wambua S, Perlmann H, Perlmann P, et al. Cytokine mRNA expression and iron status in children living in a malaria endemic area. Scand J Immunol. 2005;61:370-5.

25. Li G, Pone EJ, Tran DC, Patel PJ, Dao L, Xu Z, et al. Iron inhibits activation-induced cytidine deaminase enzymatic activity and modulates immunoglobulin class switch DNA recombination. JBiolChem. 2012;287:21520-9. 
26. Shalit M, Tedeschi A, Miadonna A, Levi-Schaffer F. Desferal (desferrioxamine) - a novel activator of connective tissuetype mast cells. JAllergy Clin Immunol. 1991;88:854-60.

27. Mecheri S, Peltre G, Lapeyre J, David B. Biological effect of transferrin on mast cell mediator release during the passive cutaneous anaphylaxis reaction: a possible inhibition mechanism involving iron. Ann Inst Pasteur Immunol. 1987;138:213-21.

28. Theobald K, Gross-Weege W, Keymling J, Konig W. Inhibition of histamine release in vitro by a blocking factor from human serum: comparison with the iron binding proteins transferrin and lactoferrin. Agents Actions. 1987;20:10-6.

29. Theobald K, Gross-Weege W, Keymling J, Konig W. Purification of serum proteins with inhibitory activity on the histamine release in vitro and/or in vivo. Int Arch Allergy Appl Immunol. 1987;82:295-7.

30. He S, McEuen AR, Blewett SA, Li P, Buckley MG, Leufkens P, et al. The inhibition of mast cell activation by neutrophil lactoferrin: uptake by mast cells and interaction with tryptase, chymase and cathepsin G. Biochem Pharmacol. 2003;65:1007-15.

31. Nakashima K, Takeuchi T, Shirakawa T. Differentiation, distribution, and chemical state of intracellular trace elements in LAD2 mast cell line. Biol Trace Elem Res. 2005;108:105-14.

32. Roth-Walter F, Afify SM, Pacios LF, Blokhuis BR, Redegeld F, Regner A, et al. Cow's milk protein beta-lactoglobulin confers resilience against allergy by targeting complexed iron into immune cells. J Allergy Clin Immunol. 2021;147:321-334.e4.

33. Roth-Walter F, Gomez-Casado C, Pacios LF, MothesLuksch N, Roth GA, Singer J, et al. Bet v 1 from birch pollen is a Lipocalin-like protein acting as allergen only when devoid of iron by promoting th2 lymphocytes. J Biol Chem. 2014;289:17416-21.

34. Roth-Walter F, Pacios LF, Gomez-Casado C, Hofstetter G, Roth GA, Singer J, et al. The major cow milk allergen Bos d 5 manipulates T-helper cells depending on its load with siderophore-bound iron. PLoS One. 2014;9:e104803.
35. Hufnagl K, Afify SM, Braun N, Wagner S, Wallner M, Hauser M, et al. Retinoic acid-loading of the major birch pollen allergen bet $\mathrm{v} 1$ may improve specific allergen immunotherapy: in silico, in vitro and in vivo data in BALB/c mice. Allergy. 2020;75:2073-7.

36. Hufnagl K, Ghosh D, Wagner S, Fiocchi A, Dahdah L, Bianchini R, etal. Retinoic acid preventsimmunogenicity of milk lipocalin Bos d 5 through binding to its immunodominant T-cell epitope. Sci Rep. 2018;8:1598.

37. Roth-Walter F, Berin MC, Arnaboldi P, Escalante CR, Dahan S, Rauch J, et al. Pasteurization of milk proteins promotes allergic sensitization by enhancing uptake through Peyer's patches. Allergy. 2008;63:882-90.

38. Jensen-Jarolim E, Pacios LF, Bianchini R, Hofstetter G, RothWalter F. Structural similarities of human and mammalian lipocalins, and their function in innate immunity and allergy. Allergy. 2016;71:286-94.

39. Roth-Walter F, Schmutz R, Mothes-Luksch N, Lemell P, Zieglmayer P, Zieglmayer R, et al. Clinical efficacy of sublingual immunotherapy is associated with restoration of steady-state serum lipocalin 2 after SLIT: a pilot study. WorldAllergy Organ J. 2018;11:21.

40. AfifyS, Pali-Schöll I, Hufnagl K, Hofstetter G, El-Bassuoni M, Roth-Walter F, et al. Bovine beta-lactoglobulin crossprotects against pollen allergies in an innate manner in $\mathrm{BALB} / \mathrm{c}$ mice: potential model for the farm effect. Front Immunol. 2021;12:611474.

41. Bartosik T, Afify SM, Petje LM, Bastl M, Berger U, Hufnagl K, et al. Dietary supplementation with a new immune tablet ameliorates human symptom load during birch pollen season: lower B-cell numbers yet with higher intracellular iron. EAACICongress. 2020. Abstract 1213.

42. Bergmann K-C, Graessel A, Raab J, Banghard W, Krause L, Becker S, et al. Targeted micronutrition via holo-BLG based on the farm effect in house dust mite allergic rhinoconjunctivitis patients-first evaluation in a standardized allergen exposure chamber. Allergo J Int. 2021; https://doi.org/10. 1007/s40629-021-00163-9. 